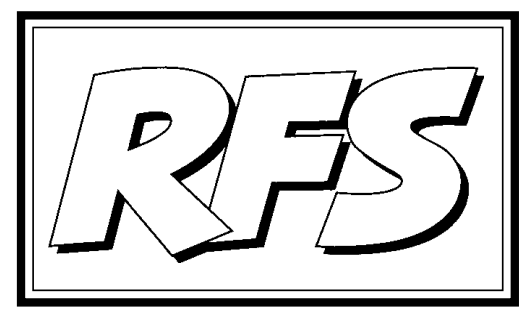

Revista de Fomento Social, 57 (2002), 175-181

\title{
XIV Reunión del Grupo Fomento Social
}

(Madrid, 24-25 diciembre 2001)

\section{Ildefonso CAMACHO LARAÑA SJ}

El Grupo Fomento Social celebró su encuentro anual en la Casa de Espiritualidad de las Esclavas del Sagrado Corazón, en Madrid (c/ General Martínez Campos), el fin de semana 24 y 25 de noviembre pasados, después de un año de interrupción. En efecto, en 2000 este encuentro anual no tuvo lugar porque casi en las mismas fechas ( 8 al 10 de diciembre) se celebraron en Alcalá de Henares las J ornadas Sociales de la Compañía de J esús. De ellas dimos cumplida cuenta en nuestra revista ${ }^{2}$.

Los 30 jesuitas (entre ellos, tres portugueses y un italiano) que asistieron en esta ocasión reflexionaron, como tema de fondo, sobre: "Las nuevas formas de trabajo". La ponencia marco corrió a cargo de Eduardo Rojo Torrecilla, Profesor de la Universidad de Girona y miembro de "Cristianisme

1 Profesor de la Facultad de Teología de Granada y de ETEA.

2 A ellas se dedicó el $n$. 220 de nuestra revista (octubre-diciembre 2000): en él se recogieron los trabajos allí presentados y algunos documentos complementarios. 
i Justícia" de Barcelona. El encuentro se completó con la presentación de experiencias y comunicaciones por parte de algunos de los asistentes, así como con un espacio de reflexión sobre las actividades sociales de la Compañía de J esús y el lugar que ocupa en ellas el Grupo Fomento Social.

\section{El tema de fondo: "Las nuevas formas de trabajo"}

La ponencia que presentó Eduardo Rojo ("Reflexiones sobre los cambios en el mundo del trabajo. Dela cantidad a la calidad. Nuevos empleos y nuevos trabajadores") era de considerable extensión. Por ello se limitó a analizar con más detalle algunos puntos de la misma.

Comenzó exponiendo algunas de las condiciones más relevantes del trabajo en la actualidad. Hay que partir de la constatación de que las funciones que clásicamente se asignaron al trabajo (percepción de una remuneración, inserción social, autorrealización) no siempre las cumple ya de manera unívoca. Subrayó también cuán variables son otras circunstancias que rodean al trabajo, a diferencia de lo que ocurría en tiempos pasados. Y citó como ejemplos: los tipos de trabajo, los lugares donde éste se desarrolla, los horarios que se establecen, las formas de regulación contractual... Todo ello va unido al paso del trabajo industrial como actividad laboral dominante al trabajo de los servicios.

También se dan cambios notables en lo que se refiere a la demografía relativa al trabajo, no sólo porque desciende la población joven y se incrementa la más madura, sino por la presencia creciente de trabajadores inmigrantes, fenómeno éste que tenderá a crecer.

Analizó a continuación la incidencia de las nuevas tecnologías sobre el empleo: si en Europa el acceso a ellas no es un problema muy agudo, no puede ignorarse el peligro de que se produzca una verdadera "fractura digital", que margine a los que están incapacitados para manejar estas tecnologías. Tampoco es evidente que el uso de éstas mejore las condiciones de trabajo: aunque la tónica general es de mejora, existen excepciones que no cabe menospreciar.

No es raro oír que vamos hacia menos cantidad y más calidad en el trabajo. Pues bien, tampoco esa afirmación es exacta sin más. La reducción del tiempo de trabajo existe en términos de promedio, pero hay sectores y colectivos sociales para los que dicho tiempo aumenta, en gran parte porque es la única forma que tienen de conservar su status social. La desregulación 
de los mercados laborales es, sin duda, la principal causa de ello.

Respecto a la creación de nuevos empleos, es bien sabido que esto ocurre sobre todo en el sector servicios, tanto en servicios a las empresas (consultorías, etc.) como en servicios sociales (en el ámbito del desarrollo local, medioambiental o de la calidad de vida). La destrucción de empleo en la industria sigue siendo significativa, mientras que la construcción es más variable, dependiendo de la coyuntura. Dos circunstancias cabe añadir: el aumento de los inmigrantes, especialmente en la construcción, y el frecuente recurso a la subcontratación para la creación de empleo (pero, ¿con qué calidad?).

En relación con España, destacó el ponente algunos problemas específicos: la baja tasa de actividad femenina, el alto porcentaje de temporalidad, el predominio de la pequeña y mediana empresa (con escasos incentivos para crear empleo), los elevados índices de siniestralidad laboral, la forma como se financia la política de empleo...

En suma, el problema central del trabajo hoy es cómo conciliar una mayor flexibilidad laboral con una mayor seguridad para el empleo. A este respecto terminó su exposición con algunas propuestas de actuación:

1. Combinación de políticas económicas, de flexibilidad laboral pactada, y sociales para posibilitar la inserción laboral.

2. Intervención más activa del sector público y la iniciativa social, al tiempo que se potencia la prestación de servicios a las personas mayores dependientes.

3. Creación de empleo en el ámbito local y desarrollo de los nuevos yacimientos de empleo.

4. Políticas de promoción de la igualdad entre sexos como elemento básico de la inserción social.

5. Modernización de los sistemas de protección social adecuándolos a las nuevas estructuras familiares y al aumento de las expectativas de vida.

6. Regulación coordinada de las rentas mínimas de inserción para eliminar la heterogeneidad de las políticas seguidas por las diferentes comunidades autónomas.

7. Potenciación de la economía social solidaria e impulso a las empresas de inserción. 
8. Políticas de formación para el aprendizaje permanente, adaptadas a las necesidades de cada colectivo y a los itinerarios de inserción laboral.

En el diálogo, que siguió a la ponencia durante toda la mañana del sábado, apareció como preocupación dominante entre los asistentes el hecho de las migraciones en toda su complejidad. Otras cuestiones que salieron a relucir en el debate fueron: la economía sumergida y su incidencia sobre el paro y el empleo, la situación del empleo rural, los efectos psicológicos del desempleo.

\section{Presentación de experiencias y comunicaciones}

Fueron presentadas un total de ocho, que se dividieron en dos bloques: las cuatro primeras respondían más al modelo de comunicación, mientras que las cuatro restantes tenían más bien carácter informativo. Ocuparon la tarde del sábado 24.

1a) ILdefonso CAMACHO, Globalización y gobernabilidad: algunas propuestas recientes sobre la creación de un sistema de gobierno global. El autor, profesor en la Facultad de Teología de Granada y en ETEA de Córdoba, presentó un reciente informe de un grupo de expertos a la COMECE (Commission des Épiscopats de la Communauté Européenne) ${ }^{3}$, que ha sido la continuación de los trabajos iniciados en el Congreso Social celebrado en Bruselas (31 de marzo y 1 de abril de 2000) sobre la responsabilidad de Europa para el desarrollo global. En la exposición se detuvo en lo más novedoso del texto, que es la propuesta de crear un sistema de gobierno mundial como exigencia del proceso actual de globalización. Este sistema se estructuraría a tres niveles complementarios: la cooperación de los gobiernos y agentes sociales en general; el reforzamiento de los actuales organismos internacionales; la creación de un órgano en que estuvieran presentes un número significativo de jefes de Estado y de gobierno (unos de modo permanente y otros por rotación mediante procedimientos electivos).

2a) J OSÉ I GNACIO GARCía J IMÉNEZ, Empleo e inmigración en el medio rural. Esta comunicación tenía por objeto estudiar las posibilidades de crear empleo en la comunidad de Castilla-León para detener su tendencia al decrecimiento

3 El documento, cuyo texto sólo está por ahora disponible en inglés, lleva por título: Global governance. Our responsability to make globalisation an opportunity for all. A report to the Bishops of COMECE, Brussels, September 2001. 
demográfico (su autor es profesor en INEA, Valladolid). Sin embargo, la posibilidad de atraer mano de obra inmigrante para el sector rural choca con el predominio que se da en él del empleo autónomo y del temporero. Por otra parte ese medio rural, tan despoblado y envejecido, apenas demanda empleo. En todo caso, si Castilla-León ve en la inmigración una vía para hacer frente a su decadencia demográfica, tiene que poner en marcha una política atractiva para los inmigrantes y para la creación de empleo rural.

3a) Alberto López Caballero, Nuevas formas de trabajo y sindicatos. Tomando como perspectiva para su exposición la situación actual de los jóvenes profesionales, su autor (profesor jubilado de la Universidad Comillas) analizó dos tipos de empresa: el modelo tradicional ("cadre d'entreprise"), más típico del ámbito japonés (estructura más jerárquica donde se valoran virtudes como la fidelidad, la lealtad, la disciplina) y el modelo más moderno ("cadre de réseau") que potencia la iniciativa y el protagonismo del profesional, más atento a su propia realización y al deseo de autonomía. En la actual situación se proponía una estrategia completiva que recoja lo que de más positivo hay en cada modelo.

4ạ) J avier Martínez Cortés, Las "torres gemelas" ¿han sepultado ortodoxias económicas (también)? El atentado que hizo derrumbarse a las torres gemelas de Nueva York encierra no pocos argumentos contra el neoliberalismo reinante y muestra las debilidades de la liberalización: porque sin Estado ni servicios públicos no hay seguridad. Y es que el neoliberalismo es una filosofía útil para los buenos tiempos. Pero, desgraciadamente, parece que las creencias son inmunes a las evidencias empíricas. Por eso su autor (profesor jubilado de la Universidad Comillas) terminaba preguntando si no era necesario un mayor esfuerzo intelectual para el debate con el neoliberalismo.

5a) Miguel Lorente Páramo, Reunión de J esuitas Científicos Europeos (Málaga, septiembre 2001). Tras hacer un breve recorrido por la historia de la Compañía de J esús para poner de relieve su interés permanente por la ciencia y el diálogo con ella, Miguel Lorente (catedrático de la Universidad de Oviedo) dio cuenta de la reciente VII Reunión de los J esuitas Científicos de Europa. En ella se elaboró una declaración de la misión, en la que los participantes quisieron expresar cómo viven su vocación cristiana y jesuita en en mundo científico. Leyó y comentó el texto de dicha declaración.

6a) Josep F. Mària Serrano, La red jesuita sobre globalización. Sobre este proyecto ya informó él mismo (profesor de ESADE, Barcelona) en el encuen- 
tro de hace dos años. Se trata de un proyecto coordinado desde la Universidad de Georgetown (Washington) cuyo objeto es estudiar los efectos de la globalización económica sobre las culturas. Ahora se dio a conocer el estado del proyecto, que está en la fase de encuentros regionales. En este momento se prepara el encuentro correspondiente a Europa.

7ạ) Julio Martínez Martínez, Reunión de EUROJESS (Berlín, agosto 2001). Como asistente a este encuentro de los jesuitas que se interesan por los problemas sociales, Julio Martínez (profesor de la Universidad Comillas) informó detenidamente sobre su desarrollo. Fue tema de este año: "Los rostros de la inmigración". Los 50 jesuitas asistentes combinaron la reflexión, a partir de las ponencias preparadas, con los experiencia, a través de instituciones que se mueven en contacto directo con los inmigrantes. Como conclusión, paradójica sin duda, de todo ello se podría decir: se ha derrumbado un muro, pero se han levantado otros ${ }^{4}$.

8a) Lluis Recolons Arquer, Realizaciones y proyectos de la Red SJ Internacional sobre Población y Pobreza (International Population Concerns). El autor, que es Director de Migra-Studium de Barcelona, comenzó mostrando el libro, recientemente publicado, que recoge las ponencias del encuentro celebrado por este grupo en Nueva Delhi en octubre de $1999^{5}$. Informó luego de algunas otras actividades del grupo o de algunos de sus miembros. Se detuvo especialmente dando cuenta de la organización de un próximo encuentro del grupo en El Cairo (septiembre 2003) sobre ética de la población, con particular atención a las posiciones cristiana e islámica sobre población, familia, etc.

\section{El Grupo Fomento Social y el apostolado social de la Compañía de J esús en España}

La mañana del domingo 25 comenzó con una breve intervención de Sergio Sala, jesuita italiano que ayuda al director del Secretariado Social de la Compañía de J esús. Informó sobre las distintas tareas que lleva a cabo en el presente dicho Secretariado, refiriéndose especialmente a la situación del

4 Véase su crónica en el no224 de nuestra Revista de Fomento Social (octubre-diciembre 2001), dedicado a las migraciones, pp. 707-714.

5 Stan d'Souza (ed.), Population and Poverty Issues at the Dawn of the 21st Century, Indian Social Institute, New Delhi 2001, 145-158. 
apostolado social entre los jesuitas deEuropa y los pasos dados para reforzar los contactos en red entre ellos.

A continuación intervino el P. Provincial de la Compañía de Jesús en España, Isidro González Modroño, que introdujo la reflexión sobre el apostolado social de la Compañía en nuestro país exponiendo los pasos dados y las tareas inmediatas. Se refirió a la puesta en marcha de la nueva Comisión Interprovincial de Apostolado Social (CIAS), que tendrá que asumir las prioridades formuladas en el Encuentro de Alcalá de diciembre del año pasado, promover la coordinación nacional de los diversos subsectores de trabajo, apoyar algunas presencias institucionales de la Compañía en el sector social de España y hacer que funcione una especie de centro de reflexión sobre temas sociales que trabaje en red.

El intercambio que siguió a esta exposición se centró en el lugar que corresponde a este Grupo Fomento Social en el marco trazado: este Grupo debería funcionar como un espacio para el encuentro de jesuitas, del sector y de fuera de él, interesados en la dimensión social de los problemas, que se encuentran periódicamente para la profundización y el debate.

\section{Conclusión}

En encuentro terminó con la asamblea estatutaria del Grupo, en la que se hizo la evaluación de la sesión de este año. Se decidió también que el año próximo el encuentro se celebre en Córdoba, lo que permitirá conocer de cerca la actividad de INSA-ETEA como institución de la Compañía de Jesús que desempeña una importante actividad en el sector social. 